\title{
Quinone Redox-active Ionic Liquids
}

Andrew Patrick Doherty, ${ }^{1}$ Sean Patterson, ${ }^{1}$ Laura Diaconu, ${ }^{1}$ Louise Graham, ${ }^{1}$ Rachid Barhdadi, ${ }^{2}$ Valentin Puchelle, ${ }^{2}$ Klaudia Wagner, ${ }^{3}$ David L Office ${ }^{3}$ and Jun Chen ${ }^{3}$ and Gordon G Wallace ${ }^{3}$

1 School of Chemistry and Chemical Engineering, The Queens's University of Belfast, Belfast, Northern Ireland, BT9 5AG, United Kingdom.

e-mail a.p.doherty@qub.ac.uk, telephone + 44 (0)2890974481, fax + 44 (0)28906524

2 Université Paris-Est Créteil, IEES Paris - DIIM, 61, Avenue du General de Gaulle, 94010 CRETEIL Cedex, France

3 Intelligent Polymer Research Unit, ARC Centre of Excellence for Electromaterials Science, University of Wollongong, Wollongong, NSW, Australia

Received November $17^{\text {th }}, 2015$; Accepted January $18^{\text {th }}, 2016$

\begin{abstract}
Simple ionic liquids exhibit unique physical and chemical properties that make them very useful for deployment in electrochemical devices such as solvent-free electrolytes in capacitors and batteries. However, incorporating redox functionality into ionic liquid structures opens up in situ faradaic electrochemistry which allows access to a large array of new electrochemical applications reliant upon heterogeneous or homogenous electron-transfer processes. This paper presents and discusses the opportunities and challenges for these types of electro-materials across a myriad of applications by considering exemplar quinone-functionalised ionic liquids.
\end{abstract}

Key words: task specific ionic liquids; redox active; applications; electrochemical devices.

\section{Introduction and perspective}

Air and moisture stable room temperature ionic liquids (RTILs) were first reported by Wilkies and Zaworotko [1] in 1992. The materials reported were simple imidazolium salts of acetate $([\mathrm{Ac}])$ and tetrafluoroborate $\left(\left[\mathrm{BF}_{4}\right]\right)$ as depicted in Fig. 1. This development represented a technical step-change from the earlier chloroaluminate molten salts [3] which were notoriously unstable under ambient conditions and thus opened up a vast array chemical and electrochemical possibilities which have been exploited ever since. The key physical or physiochemical properties that RTILs which make them attractive exhibit include

i) Inherent ionic conductivity (typically $\mathrm{mS} \mathrm{cm}^{-1}$ range),

ii) inert / extreme redox robustness (up to $7 \mathrm{~V}$ potential window reported),

iii) non-volatile / non-flammable,

iv) high charge carrier concentration $\left(>>1 \mathrm{~mol} \mathrm{~L}^{-1}\right)$,

v) thermal stability,

vi) liquid state at low temperatures.

In addition to these favourable properties the idea of incorporating chemical functionality into the RTIL structure to create task-specific ionic liquids (TSILs) $[4,5]$ has contributed greatly to the development of unique applications beyond their
Resumen. Los líquidos iónicos simples exhiben propiedades físicas y químicas únicas, lo que los hace de utilidad en dispositivos electroquímicos, funcionando como electrolitos libres de disolvente en capacitores y baterías. Sin embargo, la incorporación de funcionalidades redox en las estructuras de líquidos iónicos permite realizar electroquímica faradaica in situ, abriendo una nueva categoría de aplicaciones electroquímicas relevantes como procesos de transferencia electrónica heterogénea u homogénea. Este trabajo presenta y discute las oportunidades y retos en la generación de estos nuevos materiales sobre diversas aplicaciones, ejemplificadas mediante el uso de líquidos iónicos funcionalizados con grupos quinona.

Palabras clave: líquidos iónicos de tarea específica; electroactividad; aplicaciones; dispositivos electroquímicos.

use as simple electrolytes or solvents. Although Davis' 2004 paper [5] formally introduced TSILs, examples of ILs with built-in electro-active functionality were already known in the literature; for example, Murray et al. incorporated both quinone [6] and metal complexes [7] into "molten salt" structures while viologen IL materials were reported in 2003 [8]. Contemporaneous to Davis, other work by Shreeve et al. [9] and Park et al. [10] concentrated on the incorporating of ferrocene ( $\mathrm{Fc})$ moieties (as functionalise cations) and $\mathrm{I}^{-}$(as anions), respectively. These works appeared in 2004 while $\mathrm{Wu}$ et al. [11]

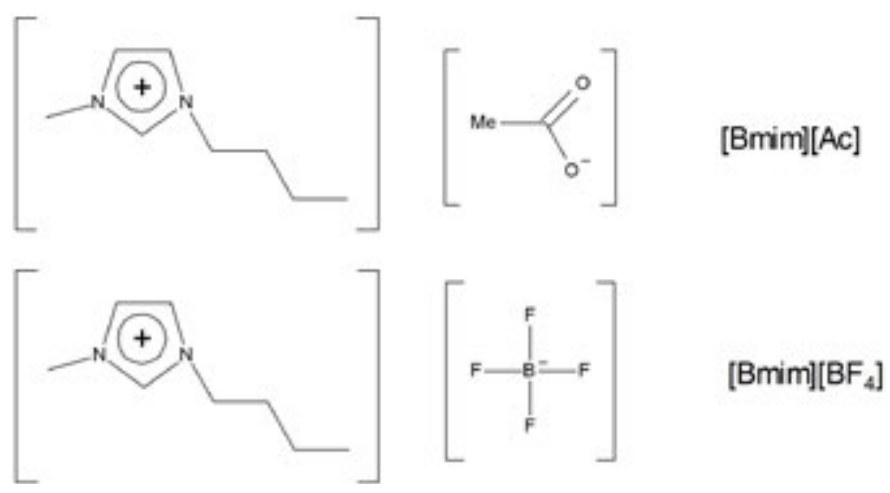

Fig. 1. Structures of first stable room temperature ionic liquids [1]. 
subsequently reported the incorporation of the redox catalyst TEMPO (2,2,6,6-tetramethylpiperidine-1-oxyl) into imidazolebases salts which were solids in their native state at RT but soluble in conventional ILs. More recently, Strehmel et al. [12] reported a TEMPO-based RTIL which acted as a radical probe in ILs.

It is probably not coincidental that these early examples emerged from classical molecular electrochemistry and that they all point in the direction of important technical applications such as enzyme redox catalysis $\left(\mathrm{Fc} / \mathrm{Fc}^{+}\right)$, dye sensitizes solar cells $\left(\mathrm{I}^{-} / \mathrm{I}_{3}^{-}\right)$(DSSCs), hydrogen peroxide generation (quinone/hydroquinone) and alcohol oxidations (TEMPO/nitrosonium). Presenting these and other well-known electrochemistries in appropriate IL form will lead to new or improved electrochemical technologies including the aforementioned but also including redox flow batteries, thermal batteries, and super-capacitors. Since most of these applications involve the harvesting and energy storage functions their emergence and exploitation may impact significantly on the energy landscape in the foreseeable future.

Students of molecular electrochemistry and redox catalysis can easily trace the evolution of the field from homogeneous-bases (i.e. solution-based) processes to heterogenised systems with the advent of chemically modified electrodes in the early 1980s [13], in particular, for redox catalytic systems based on surface confined redox centres (2-D) or for polymer-confined (3-D) systems. In principle, heterogenising these chemistries obviated, or simplified, the recovery of valuable redox catalysts from complex reaction liquor, or facilitated the construction of selective thin-film or thin-layer electrochemical devices such as sensors or DSSCs.

Because ILs can be designed to facilitate product recovery [4] and are inherently non-volatile, redox active ionic liquids can be viewed as a further evolution in molecular electrochemistry / redox catalysis / redox mediators despite presenting themselves as bulk liquids. Indeed, bulk liquids have the advantage of scaling by volume rather that by area in synthetic and energy storage applications so are valuable per se. Also, in terms of thin film type applications (e.g. sensor) Toniolo et al. [14] have already successfully demonstrated an $\mathrm{O}_{2}$ electrochemical sensor deploying an anthraquinone based redox catalytic ionic liquid.

A third possibility for deployment of redox active ionic liquids is as a "sandwich" device i.e. positioned between two active electrodes e.g. as electron transfer mediators in DSSCs or as "redox-active electrolytes" in capacitors. For the latter, such systems would act as supercapacitors since they will harness the faradic charge stored in the built-in redox centres as well as the electrostatic capacitive charge [15]. For the former I' based ionic liquids have been reported [10].

Although ionic liquids exhibit many attractive properties a potentially serious limitation of these materials is their relatively large viscosities which typically range from ca. $20 \mathrm{cP}$ to $1000 \mathrm{~s}$ of $\mathrm{cP}$ with the common imidazolium and pyrrolidinium ILs (depending on the anion) exhibiting viscosities in the $50-$ $350 \mathrm{cP}$ range. Significantly, Gratzel et al. have shown that ion conductivity $\left(\mathrm{S} \mathrm{cm}^{-1}\right)$ in RTILs is an inverse function of viscosity [16] so for all electrochemical devices which rely on mass transport minimising viscosity is critical. Since viscosity is intrinsically dependent on the complexity (size and structural symmetry) of the cation and the nature of the anion (e.g. H-bonding ability) the design of new functional TSILs requires appropriate careful consideration. From an intuitive empirical perspective low viscosity is achieved with small non-coordinating anions paired with larger, but not too large, structurally asymmetric cations where charge delocalisation is extensive for both ions. Even for simple RTILs, they only exist as liquids over a fairly narrow range of structures. Obviously, adding functionality to RTILs inevitably increases mass, and frequently increases structural symmetry and inter-molecular attractive forces all of which favour solidification; these restrictions imposes severe challenges to molecular design of TSILs.

In addition to minimising viscosity the following functional requirements must also be met,

- bear a permanent charge i.e. be a RTIL in both redox states,

- exhibit reversible electrochemistry,

- be catalytic i.e. appropriate $\mathrm{E}^{0}$ for redox catalysis,

- be otherwise inert,

- be either hydrophobic or hydrophilic as application requires.

Although there are many well-known redox chemistries to choose from the syntheses, characterisation and electrochemistry of some novel quinone-based ionic liquids will be presented and discussed here in terms of their potential for application in real electrochemical devices and processes, in particular as $\mathrm{O}_{2}$ reduction redox catalysts. The core quinone structure is shown in Fig. 2.

\section{Experimental}

Synthesis of 9,10-anthraquinone-2-sulfonate functionalized ionic liquids. Sodium anthraquinone-2-sulfonate ([Na][AQS]) was obtained from Aldrich. The sulfonate anion provided the common anion for a suite of familiar quaternary ammonium and phosphonium ionic liquid cations (Table 1). A series of chloride

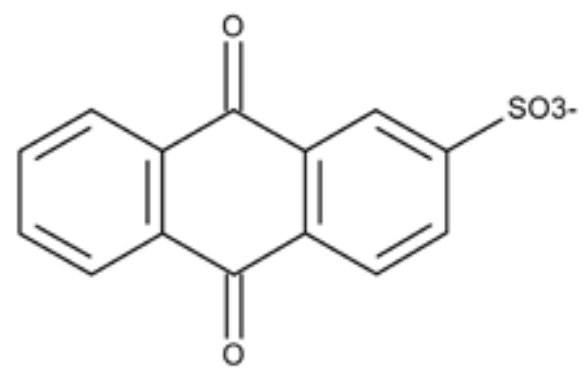

Fig. 2. Structure of core electro-active centre and anion of quinone electro-active ionic liquids. 
salt of these cations were reacted with sodium anthraquinone-2-sulfonate in toluene for $48 \mathrm{Hrs}$. with constant stirring after which the $\mathrm{NaCl}$ precipitate was removed by filtration (No. 4 sintered glass filter). The resultant liquor was washed repeatedly with deionised water to remove residual $\mathrm{NaCl}$. The toluene was removed under vacuum to reveal the salt product. Details of their melting points and hydrophobicity are given in Table 1.

Electrochemical Measurements. All electrochemical measurements were performed using a three-electrode potentistat, either a Voltalab 40 (Radiometer) or a Digi Ivy 2100 mini-potentiostat. The working electrode in all experiments were $3 \mathrm{~mm}$ diameter glassy carbon (from Bioanalytical Systems (BAS)) while the counter electrodes were Pt wire (Goodfellow) sealed in glass. The working electrodes were polished with $0.05 \mu \mathrm{m}$ $\gamma$-alumina prior to use. The reference electrodes were either aqueous $\mathrm{Ag} / \mathrm{Ag}^{+}$(from BAS, $1.0 \mathrm{M} \mathrm{AgNO}_{3}$ ), a saturated calomel electrode (SCE) or a Pt wire quasi-reference electrode $\left(\mathrm{Pt}_{\mathrm{ss}}\right)$. Details of electrolytes and solvents used are given in the text and/or in Figure legends.

\section{Results and Discussion}

Preliminary observations: The accepted definition of RTILs is salts which have melting points $\leq 100{ }^{\circ} \mathrm{C}$. Despite this generous technical definition practical considerations desire, or demand, much lower melting points, for example to facilitate enzyme electrochemistry or to prevent accidental solidification of the functional liquid in reactors during shut-down etc. Inspection of the data in Table 1 indicates that only one of the ten anthraquinone-2-sulfonate is liquid at $293 \mathrm{~K}$ and that only two out of these ten fall within the accepted upper melting point limit defining RTILs. These observations are not surprising since the symmetry and planarity of the AQS core, coupled with the significant pi-pi inter-molecular interaction between quinone molecules increases the likelihood of long-range order so solidification rather than liquefaction is likely.

Table 1. 9,10 anthraquinone-2-sulfoate salts and their properties.

\begin{tabular}{lcc}
\hline Cation & Melting point $\mathbf{~}^{\mathbf{0}} \mathbf{C}$ & Hydro- \\
\hline $\mathrm{P}$ & $<0.0$ & phobic \\
$\mathrm{P}^{14666}$ & $120-122$ & - \\
$\mathrm{N}^{4444}$ & $96-98$ & phobic \\
$\mathrm{N}^{8881}$ & $130-132$ & - \\
$\mathrm{N}^{4444}$ & $104-106$ & - \\
$\mathrm{N}^{10811}$ & $140-143$ & - \\
$\mathrm{N}^{12211}$ & $>250$ & - \\
$\mathrm{Bmin}_{1611} 11$ & $152-155$ & - \\
$\mathrm{N}$ & $129-131$ & - \\
BiP 8 1 & $112-115$ & - \\
\hline
\end{tabular}

$\mathrm{P}=$ phosphonium, $\mathrm{N}=$ ammonium, $\mathrm{Bmim}-=$ butylmethylimidazolium, $\mathrm{N}_{\text {PIP }}=$ piperdinium, Bmpy = butylmethylpyrrolidinium, and the numerical subscripts indicate the number of carbons on the alkyl substituents.
Electrochemistry of Anthraquinone-2-sulfonates: It is our experience that the common cation does not interfere with the electrochemistry of the quinone-bases salts therefore only the electrochemistry of [ $\left.\mathrm{P}_{14666}\right][\mathrm{AQS}]$ will be presented here. Fig. 3 shows cyclic voltammograms for $\left[\mathrm{P}_{14} 6_{6} 6\right][\mathrm{AQS}]$ in $\mathrm{O}_{2}$-free acetonitrile containing $0.2 \mathrm{~mol} \mathrm{~L}^{-1}$ tetrabutylammonium tetrafluoroborate (TBATFB) electrolyte recorded with a Digi Ivy mini potentiostat (iR compensation function unavailable). It is clear that the AQS ion undergoes two sequential and reversible electrochemical reductions via the classical two one-electron events as expected (Equations 1 and 2) resulting in the formation of stable radical anions and stable di-anion, respectively.

$$
\begin{aligned}
& \mathrm{AQS}+\mathrm{e}-\rightleftharpoons \mathrm{AQS}^{-} \mathrm{E}_{1 / 2}=-1.27 \mathrm{~V} \text { vs. } \mathrm{Fc} / \mathrm{Fc}^{+} \\
& \mathrm{AQS}^{--}+\mathrm{e}-\rightleftharpoons \mathrm{AQS}^{2-} \mathrm{E}_{1 / 2}=-1.79 \mathrm{~V} \text { vs. } \mathrm{Fc} / \mathrm{Fc}^{+}
\end{aligned}
$$

Using the Randles-Sevcik equation the diffusion coefficients (D) for both AQS and AQS ${ }^{*-}$ were determined to be $1.1 \times$ $10^{-5} \pm 0.1 \times 10^{-6} \mathrm{~cm}^{2} \mathrm{~s}^{-1}$ and $1.4 \times 10^{-5} \pm 0.3 \times 10^{-6} \mathrm{~cm} \mathrm{~s}^{-1}$, respectively. A "worst case scenario" estimation of $\mathrm{k}^{0}$, the rate of heterogeneous electron transfer, for both redox processes calculated from peak-to-peak separations $\left(\Delta \mathrm{E}_{\mathrm{p}}\right)$, is $\sim 6 \times 10^{-3}$ and $\sim 5$ $\mathrm{x} 10^{-3} \mathrm{~cm} \mathrm{~s}^{-1}$ for the first and second redox processes, respectively.

Transferring the electrochemistry to the neutral ionic liquid environment of $\left[\mathrm{P}_{14} 66_{6}\right]\left[\mathrm{NTf}_{2}\right]$ recorded with iR compensation using a Voltalab 40 potentiostat has no effect on the general electrochemistry insofar as the mechanism is the same and both the radical anions and di-anions are stable as can be seen in Fig. 4.

It is also evident from the data in Fig. 4 that due to the viscous nature of the ionic liquid the rate of mass transport is significantly reduced relative to acetonitrile where a diminution of the [AQS] diffusion coefficient from $\sim 10^{-5} \mathrm{~cm} \mathrm{~s}^{-1}$ to $5 \times 10^{-8} \mathrm{~cm}$

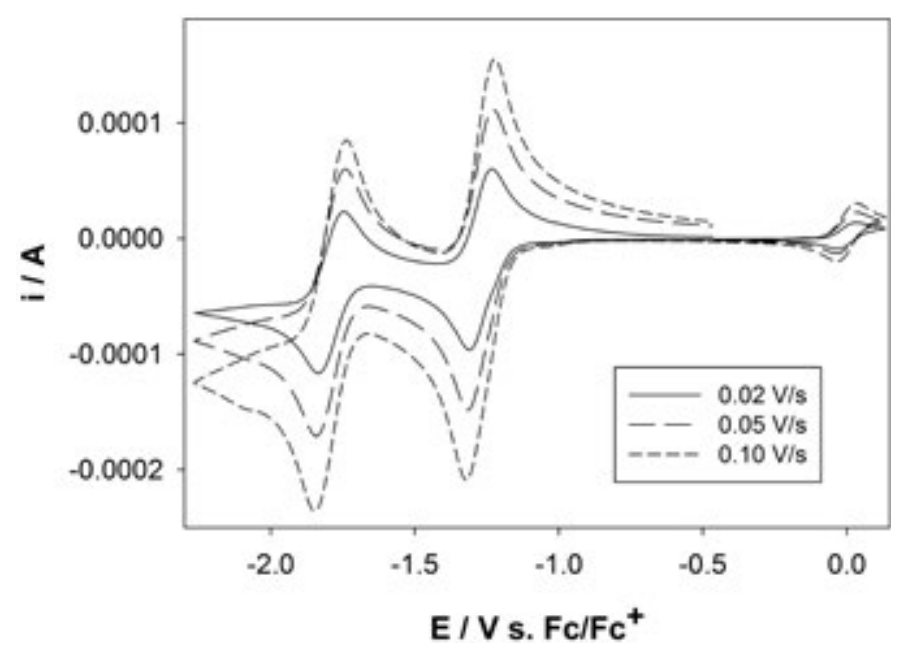

Fig. 3. Voltammograms for the reductive electrochemistry of AQS under neutral, $\mathrm{O}_{2}$-free conditions in acetonitrile with $0.2 \mathrm{~mol} \mathrm{~L}^{-1}$ TBA TFB electrolyte. The peaks at $0.0 \mathrm{~V}$ are $\mathrm{Fc} / \mathrm{Fc}^{+}$internal potential standard. 


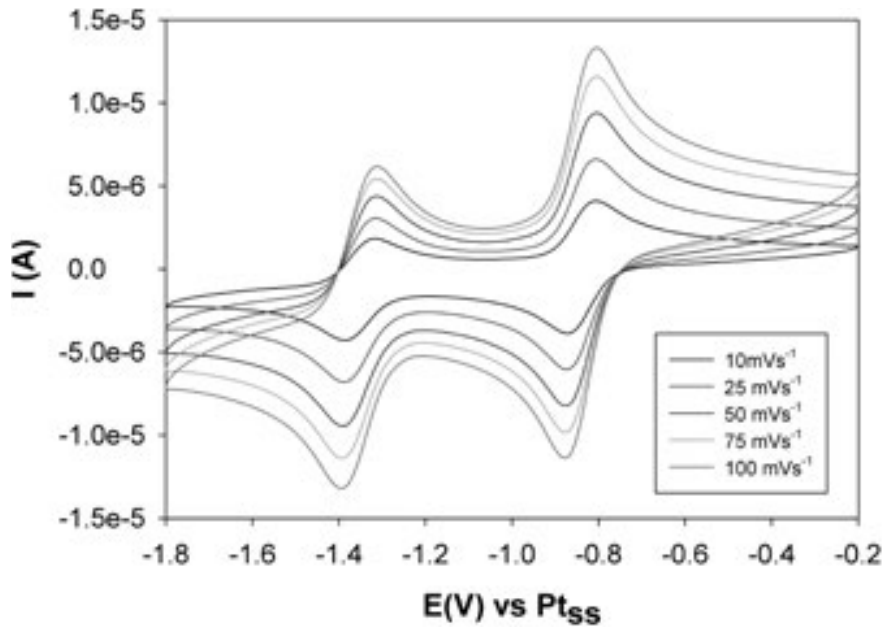

Fig. 4. Cyclic voltammograms of $1.0 \times 10^{-5} \mathrm{~mol} \mathrm{~cm}^{-3}\left[\mathrm{P}_{14666}\right][\mathrm{AQS}]$ in $\left[\mathrm{P}_{1466} 6_{6}\right]\left[\mathrm{NTf}_{2}\right]$ ionic liquid.

$\mathrm{s}^{-1}$ is evident. On the positive side, $\mathrm{k}^{0}$ for both process is $\geq 0.1$ $\mathrm{cm} \mathrm{s}^{-1}$, a rate which is considered electrochemically reversible i.e. fast.

The electrochemical generation of AQS ${ }^{--}$was used previously by Toniolo et al. [14] to develop an ionic liquid based thin-layer $\mathrm{O}_{2}$ sensor where the sensing redox catalytic reaction was the formation of super-oxide according to Equation 3.

$$
\mathrm{AQS}^{*}+\mathrm{O}_{2} \rightleftharpoons \mathrm{AQS}+\mathrm{O}^{\bullet}
$$

Two unique features of this sensor are both worth considering; firstly, since the RTILs are non-volatility the sensor never "dries out", and secondly, the thin-film of electro-active RTIL is easily replaced to renew the sensing interface.

It is well known that quinone electrochemistry is $\mathrm{pH}$-dependent therefore the electrochemistry of $\mathrm{AQS}$ under acidic conditions $\left(0.2 \mathrm{~mol} \mathrm{~L}^{-1} \mathrm{HClO}_{4}\right)$ in acetonitrile is shown in Fig. 5. It is immediately obvious from the traces in Fig. 5 that the reduction involves a single process while the re-oxidation potential is significantly displaced anodically from the expected reversible potential. In addition, the anodic and cathodic peak potentials migrate positively and negatively with increasing potential sweep-rate, respectively. This behaviour is the classical electrochemistry for quinones under the influence of complex acid-base equilibrium processes coupled with electron transfer [17]. What is clear from Fig. 5 is that the overall electrochemical reduction process under acidic conditions is a single process occurring at $c a .0 .2 \mathrm{~V}$ vs $\mathrm{Ag} / \mathrm{Ag}^{+}$involving two electrons and two proton i.e. electrochemical hydrogenation to form the anthrahydroquinone species $\left(\mathrm{AH}_{2} \mathrm{QS}\right)$ according to Equation 4 . The literature value for the reversible $\mathrm{AQS} / \mathrm{AH}_{2} \mathrm{QS}$ process is 0.225 vs SHE [18].

$$
\begin{aligned}
\mathrm{AQS}+2 \mathrm{e}-+2 \mathrm{H}^{+} \rightleftharpoons & \mathrm{AH}_{2} \mathrm{QS} \\
& \mathrm{E}_{\mathrm{pc}}=-0.160 \mathrm{~V} \text { vs. } \mathrm{Ag} / \mathrm{Ag}^{+}
\end{aligned}
$$

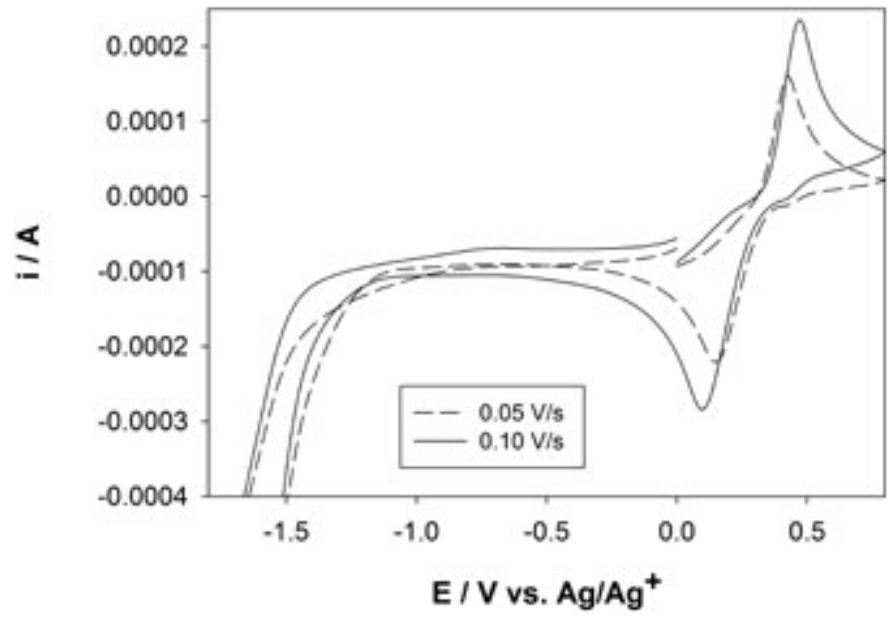

Fig. 5. Cyclic voltammograms of the reductive electrochemistry of $1.0 \times 10^{-5} \mathrm{~mol} \mathrm{~cm}^{-3}\left[\mathrm{P}_{14666}\right][\mathrm{AQS}]$ in acetonitrile with $0.2 \mathrm{~mol} \mathrm{~L}^{-1}$ TBA TFB and $0.2 \mathrm{~mol} \mathrm{~L}^{-1} \mathrm{HClO}_{4}$ electrolyte under $\mathrm{O}_{2}$-free acidic conditions.

AQS electrochemistry in $\left[\mathrm{P}_{14} G_{6} \sigma_{6}\right]\left[\mathrm{NTf}_{2}\right]$ acidified with three stoichiometric equivalents (per carbonyl) of the super-acid $\mathrm{HNTf}_{2}$ is shown in Fig. 6 where it is clear that the reduction occurs in a chemically reversible fashion but $\Delta \mathrm{E}_{\mathrm{p}}$ (peak-to-peak separation) of up to $500 \mathrm{mV}$ suggest significant influence of coupled proton transfer equilibria at play within the non-aqueous IL environment. Overall, the electrochemistry occurs via the expected 2-electron / 2-proton mechanism leading to the redox-catalytic hydroquinone form

It is well known that anthrahydroquinones are very useful reducing agents with $\mathrm{O}_{2}$ reduction to $\mathrm{H}_{2} \mathrm{O}_{2}$ being used commercially to produce millions of tonnes of peroxide annually. This second-order [19] chemical process is known as auto-oxidation and exploits $\mathrm{H}_{2}$ rather than electricity as the energy source. In

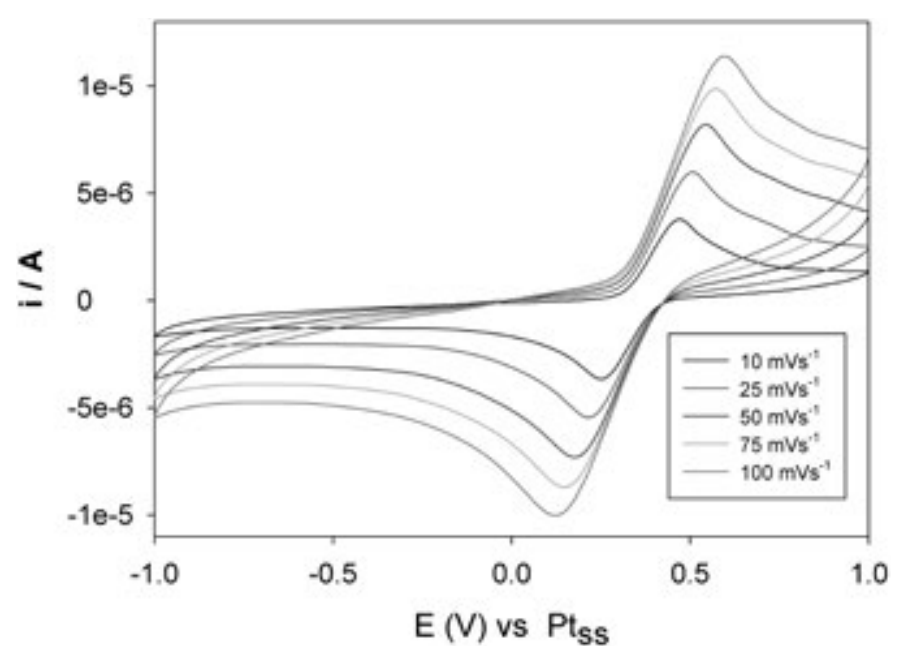

Fig. 6. Cyclic voltammograms of the reductive electrochemistry of 1.0 $\times 10^{-5} \mathrm{~mol} \mathrm{~cm}^{-3}\left[\mathrm{P}_{14666}\right][\mathrm{AQS}]$ in $\left[\mathrm{P}_{14666}\right]\left[\mathrm{NTf}_{2}\right]$ acidified with three stoichiometric equivalents (per carbonyl) of $\mathrm{HNTf}_{2}$. 
order to assess the reactivity of the electro-generated $\mathrm{AH}_{2} \mathrm{QS}$ towards $\mathrm{O}_{2}$ reduction oxygen gas was introduced into the acidic AQS solution (equilibrated at $1 \mathrm{~atm} . \mathrm{O}_{2}$ atmosphere) and slowsweep-rate cyclic voltammetry recorded as depicted in Fig. 7 where a Sigmoidal curve is observed due to the steady-state catalytic current, $i_{c}$, behaviour which is indicative of redox-catalysis occurring at the electrode according to Equations 4 and 5.

$$
\mathrm{AH}_{2} \mathrm{QS}+\mathrm{O}_{2} \rightleftharpoons \mathrm{AQS}+\mathrm{H}_{2} \mathrm{O}_{2}
$$

Using Equation 6, where $\mathrm{n}$ is the number of electrons $(n=2), F$ is Faraday's constant, $A$ is the area of the electrode and $\mathrm{C}$ is the concentration of AQS $\left(1.0 \times 10^{-5} \mathrm{~mol} \mathrm{~cm}^{-3}\right)$ a forward rate constant $\left(\mathrm{k}_{\mathrm{f}}, \mathrm{s}^{-1}\right)$ can be calculated assuming pseudo-first order kinetics $\left(\left[\mathrm{O}_{2}\right]>>[[\mathrm{AQS}]]\right.$ since the solubility of $\mathrm{O}_{2}$ in pure acetonitrile is $8.1 \mathrm{~mol} \mathrm{~L}^{-1}$ [20] and $\sim \mathrm{mol} \mathrm{L}^{-1}$ in the presence of perchlorate electrolyte [21].

$$
\mathrm{i}_{\mathrm{c}}=\mathrm{nFAC} \sqrt{\mathrm{D} \mathrm{k}}
$$

For the highly acidic solution $\left(0.2 \mathrm{~mol} \mathrm{~L}^{-1} \mathrm{HClO}_{4},=\mathrm{pH} 0.7\right.$ assuming full dissociation) with saturated $\left[\mathrm{O}_{2}\right], \mathrm{k}_{\mathrm{f}}$ was found to be $0.03 \mathrm{~s}^{-1}$ which corresponds to a $2^{\text {nd }}$ order rate constant of 3.0 $\mathrm{mol}^{-1} \mathrm{~L} \mathrm{~s}^{-1}$. Although relatively slow, this rate is somewhat faster than the rate of $\mathrm{AQ}$ hydrogenation using $\mathrm{H}_{2}$ in catalytic slurry reactors e.g. $\sim 0.02 \mathrm{~mol} \mathrm{~m}^{-3} \mathrm{~s}^{-1}$ [22]. Because the $\mathrm{E}^{0}$ for AQS/ $\mathrm{AH}_{2} \mathrm{QS}$ decreases by $58 \mathrm{mV} / \mathrm{pH}$ unit [23] and that the $\mathrm{O}_{2}$ reduction reaction is $\mathrm{pH}$-dependent through proton transfer steps

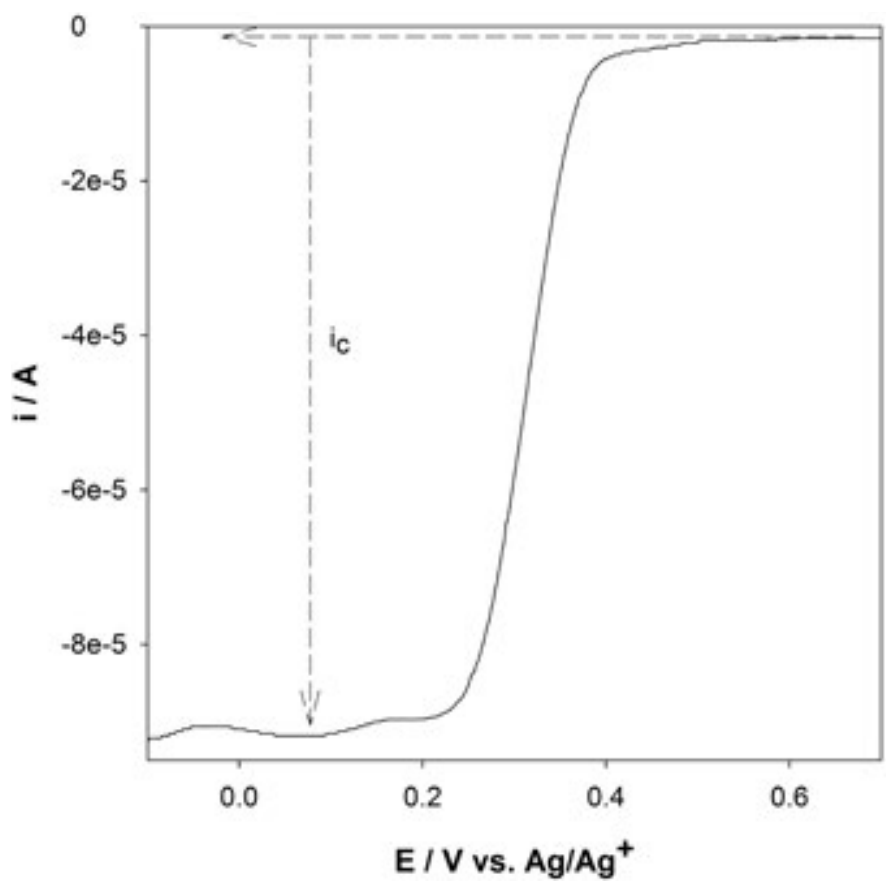

Fig. 7. Voltammogram for the reductive electrochemistry of $1.0 \times 10^{-5}$ mol cm${ }^{-3}$ AQS under acidic conditions in the presence of $\mathrm{O}_{2}(1 \mathrm{~atm}$.). The voltammogram was recorded at a potential sweep rate of $2 \mathrm{mV} \mathrm{s}^{-1}$.
(Equation 4), the rate of $\mathrm{O}_{2}$ reduction reaction will increase logarithmically with $\mathrm{pH}$ as previously found for redox catalytic alcohol oxidation reactions in ionic liquids [24].

\section{Conclusions}

Based on the simple examples shown here it is evident that building electrochemical functionality into ionic liquid "type" structure is relatively straightforward from a synthetic perspective but the likelihood of success (obtaining a RTIL) depends entirely on the nature of the anion and cation, therefore restricting synthesis to commercially available ions will inevitably severely limit the functional materials obtained. Out of the ten examples shown here it is no coincident that $\mathrm{P}_{14666}$ exemplar "works" because it, even as the chloride salt, behaves effectively as an oil rather that as solid salt. In terms of deploying these types of materials, whether RTIL or not, it should be kept in mind that they are soluble/miscible in RTILs with a common counter-ion e.g. in low viscosity carrier ILs such as [Bmim] $\left[\mathrm{NTf}_{2}\right]$ and thus the "business end" of the functional salt can be deployed in RTIL form. It is also worth keeping in mind that it is the nature of that anion (usually non-coordinating) that predominantly controls the physical properties of RTILs so switching the permanent charged on the quinone to cationic present an opportunity to create redox active quinone-based RTILs with more favourable physical properties. Incorporating redox behaviour in this way for redox catalysis and redox conduction creates possibilities for new electrochemical processes and devices [25].

\section{Acknowledgments}

L. G. would like to thank the Department of Education and Learning in Northern Ireland for a PhD Studentship. L. D thanks QUB for a PhD studentship. APD and G.G.W thanks The Royal Society of London for an International Collaboration Grant.

\section{References}

1. Wilkes, J. S., Zaworotko, M. J. Chem. Commun. 1992, 13, $965-$ 967.

2. Hurley, F. H., Wier, Jr., T. P., US Patent 2,446,349 (1948).

3. Chum, H. L., Koch, V. R., Miller, L. L., Osteryoung, R. A. J. Am. Chem. Soc. 1975, 91, 3264-3265.

4. Welton,T. Chem. Rev. 1999, 99, 2071-2083.

5. Davis, J. H. Chem Lett. 2004, 33, 1072-1077.

6. Williams, M. E., Murray, R.W. J. Phys Chem. B. 1999, 103, 10221-10227.

7. Masui, H, Murray, R. W. Inorg. Chem. 1997, 36, 5118-5126.

8. Bhowmik, P. K., Haesook, H, Cebe, J. J., Burchett, R.A. Liquid Crystals, 2003, 30, 1433-1440. 
9. Gao, Y., Twamley, B., Shreeve, J. M. Inorg. Chem. 2004, 43, 2406-3412.

10. Kang, M. G. Ryu, K. S. Chanh, S. H., Park, N. G. ETRI 2004, 26, 647-652.

11. Wu, X. E., Ma, L., Ding, M.X., Gao, L.X. Synlett. 2005, 4, 607610.

12. Strehmel, V., Rexhausen, H., Strauch, P. Tet. Lett. 2008, 49, 71437145 .

13. Murray, R.W. Electroanalytical Chemistry, 1984, 13, 191-368.

14. Toniolo, R., Dossi, N., Pizzariello, A. , Doherty, A .P. , Susmel, S., Bontempelli, G. J. Electroanalytical Chem. 2012, 670, 23-29

15. Roldan, S., Blanco, C., Granda, M., Menendez, R., Santamaria, R. Angewendte Int. Ed., 2011, 50, 1699-1701.

16. Bonhote, P., Dias, A. P., Papageorgiou, N., Kalyanasundaram, K., Gratzel, M., Inorg. Chem., 1996, 35, 1168-1178.

17. DuVall, S. H., McCreery, R. L. J. Am. Chem. Soc., 2000, 122, 6759-6764.
18. Bailey, S. I., Ritchie, I. M. Electrochim Acta, 1985, 30, 3-12.

19. Levenspi, O, Godfrey, J. H., Chem. Eng. Sci., 1974, 29, $1723-$ 1730.

20. Laoire, C. O.,Mukerjee,S., Abraham, K. M., Plichta, E. J., Hendrickson, M. A. J. Phys. Chem. C, 2010, 114, 9178-9186.

21. Li, Q, Batchelor-McAuley,C., Lawrence, N. S., Hartshorne, R. S., Compton, R. G., J. Electroanal. Chem., 2013, 688, 328-335.

22. Fayyaz Khan, M F., Ramzan, O., Mukhtar, A., Shafiq, U., Khan, A. F. Res. J. of Chem. Sci., 2015, 5, 48-52.

23. Ojani, R., Raoof, J., Ebrahimi, M., Iran J. Chem. \& Chem. Eng. 2001, 20, 75-82.

24. Barhdadi, R.,Troupel, M., Comminges, C., Laurent, M., Doherty, A. P. J. Phys. Chem. B. 2012, 116, 277-282.

25. Murray, R.W. J. Electrochem. Soc. 1984, 132, 833-839. 